\title{
Responding to Healthcare Emergency Outbreak of COVID-19 Pandemic with Robotic Process Automation (RPA)
}

\author{
Damian Kedziora \\ Hanken School of Economics, Finland \\ damian.kedziora@hanken.fi
}

\author{
Kari Smolander \\ LUT University, Finland \\ kari.smolander@lut.fi
}

\begin{abstract}
During the complex emergency of COVID-19 pandemic, healthcare sector experienced challenging pressure surge, related to rapid increase in the number of infections, patient inquiries, and demand of immediate treatment. Such situation, experienced also in Finland at the Welfare Division of Turku City, required quick decision making and fast implementation of a reliable and secure technological solution that can take some of administrative burden off the shoulders of nurses' personnel. The case presents the implementation of Robotic Process Automation (RPA) technology that has already been recognized as an efficient tool at multiple business organizations, allowing to automate various commercial processes with quick returns and scalable results. The presented case discusses the drivers and outcomes of automating non-commercial, healthcare processes, as well as its impact on emergency response, operations, and society.
\end{abstract}

\section{Introduction}

Robotic process automation (RPA) is a piece of software that enables to automatically perform various business processes, formerly done by office workers (Osmundsen et al., 2019). It has lately gained the status of disruptive technology, allowing various organizations to robotize a plethora of manual tasks, processes, and supply chain segments. RPA has brought multiple types of value to companies, enabling them to reduce operational and capital expenditures, improve compliance and quality of delivery, release personnel from mundane and nonvalue-adding jobs, allowing 24/7 operations with faster processing lead times (Kedziora and Kiviranta, 2018). By now, RPA technology has been mainly implemented at commercial business organizations, and the size of its global market has been rapidly growing with a compound annual growth rate (CAGR) of 29\% during 2017-2023 (Reuters, 2018). The applications of this technology have been mainly implemented by IT professionals, despite wide attempts of key RPA software vendors to promote the concept of 'citizen developer', aimed to democratize its use and make every office worker develop their own automations in the future (UiPath, 2021).

COVID-19 pandemic outbreak can be understood as complex emergency (CE) that poses a risk of exacerbating onto severe natural disaster, due to the immediate strike of threatening external factors, such as economic problems, lack of healthcare support, decline in social interactions, and failing supply chains (Mija-Tesse et al., 2007). As complex emergencies and disasters can be triggered by pandemics, coronavirus posed the danger of causing serious social and economic disruptions, not only in countries with on-going economic difficulties or conflicts, but also across the developed and stable countries of the European Union (EU). Age and social groups of population with high-risk of communicable diseases, such as persons with existing medical conditions and the elderly, may have been more affected with multiple types of inconveniences, being unable to leave their homes, buy necessary supplies, continuously treat their various chronical diseases, as well as meet their relatives and close ones to maintain good mental condition (Connolly et al., 2004). The substantial reduction in mobility to fulfil basic human needs, caused by both personal risk assessments and restrictions in place and societal services (lockdowns), caused multitudes of people to remain at home and isolate themselves, even though there have been no conflicts, nor political disturbances in the EU for many decades. COVID-19 has also brought substantial uncertainly, rumour and societal infoxication, as the overload and contradiction of information related to the virus, lockdowns, politics, and management of social behaviours, caused many persons to feel 
insecure and seek for reliable information from their public authorities and healthcare (Fine, 2021).

Disrupted supply chains and unexpected problems of various service providers made most of organizations seek for rapid solutions to redesign processes and improve their operational capacity, resource usage, liquidity, and security, as well as ability to serve their customers and society effectively. Healthcare was also forced to quickly adapt to the new situation and implement changes to the routine tasks such as COVID-19 infection tests, vaccinating and treatments. The volumes of urgent case started to increase dramatically in some areas, which created a need for quick and efficient automation. Staaby et al. (2020) elaborated on automations of boring work and suggested focusing on robotizing not only routine and repetitive tasks, but also processes that can be characterized as 'meaningful'. Moreover, the study on automation at healthcare sector by Sampson (2020) recommended to further explore the healthcare context and identify task characteristics that relate to RPA. In line with this reasoning, our exploratory study is to address the following research questions:

1. Can RPA serve as the solution for COVID-19 emergency response?

2. What was the observed value of RPA implementation to the healthcare sector stakeholders?

\section{Literature Background}

RPA can be referred to as "an infinitely scalable virtual human that can be instructed very quickly in order to carry out operational procedures at the speed of a machine" (Lacity and Willcocks, 2016). Discovered and implemented for the first time not more than 10 years ago, it already received substantial attention among business practitioners and academia. In the practice of RPA market, software robot refers to one license with 24/7 capacity (Schmitz et al., 2019). Such a non-invasive program operating at the existing graphical user interfaces (GUI) is often associated with an enhancement and extension of former business process management (BPM) methods (Dumas et al., 2018). RPA technology emulates the actions of employees performed at different computer systems (van der Aalst et al. 2018). Most of bots act the way human employees perform tasks, by logging into systems with their own credentials, clicking and moving a mouse, filling reports, fetching data from tables, columns, and figures, verifying quality of data and sending emails (Hallikainen et al., 2018). It is not considered to be a novel core technology, but rather an umbrella term that encompasses several lightweight IT solutions, adapting and improving the resourceintense processes with a continuous plan-do-check-act
(PDCA) cycle, in a process-oriented view (Syed et al., 2020).

RPA is often supported by business process modelling frameworks and embedded in the process continuous improvement, lean and kaizen policies (Herm et al., 2021). When we start modelling a process, first we need to specify its purpose and define context, and as well as the situation for which our modelling is carried out (Imgrund et al., 2018). Another technique that can be applied in RPA implementations is process mining, understood as a method for gathering data from various systems, to use it for advanced analytics (Geyer-Klingeberg et al., 2018), which supports processes visualization and defining their role and contribution to the entire value streams, such as business operating models. Software robot can process up to few hundred steps, yet although the automated tasks can be very complex, they always need to follow clear rules (Willcocks et al., 2015). The modelled and improved processes, with eliminated waste are then reviewed with process experts or key users that participate in the initial process definition, aiming at obtaining final process version that works as basis for RPA (Wanner et al., 2018)

The key drivers of implementing RPA in the commercial setting are cost reductions, increased compliance, quality, stability and predictability of processing results, speed of delivery, improved productivity, or economic efficiency (Kedziora et al., 2021). Moreover, its reported high organizational success compared to traditional methods often lays in its short return on investment (ROI) and deployment time (van der Aalst et al., 2018), as opposed to traditional system integrations over application processing interfaces (APIs) that requires more resources and time to implement (Melville and Kohli, 2021). Tasks with the highest automation potential are based on logical rules, repetitive, mundane, straightforward, and high-volume (Rutschi and Dibbern, 2020). Software robots often bring fast improvements to operational efficiency and excellence with no radical changes, capable of processing large volumes of transactions without errors and with fast speed (Anagoste, 2018). Even though RPA is widely perceived as a powerful tool, the reported cases point at automation of some tasks inside process groups, but not the entire, end-to-end value chains, as they often require so called 'human touch', such as handling exceptions, empathy, negotiation, trust building (Santos et al. 2020). Hence, the global industry of service providers will still need human workforce for long time, even though it is certain that the job profile of each office worker shall transform and require some 
form of collaboration with software robots as hybrid workforce in various assignments (Nakayama, 2017).

We can still perceive RPA as a developing technology, as it still relies on past innovations in workflow automation and screen scraping, although RPA takes these solutions to a new level (Aguirre and Rodriguez, 2017). When software robots get complemented with components of optical character recognition (OCR), machine learning (ML), natural language processing (NLP) and voice recognition (Mendling et al., 2018), we can talk about 'intelligent automation' (IA) that allows to go beyond the basic capabilities of RPA. With help of these elements of artificial intelligence (AI), intelligent robots can act as chat/voice bots that simulate conversational activity, navigate at virtualized desktops in order to help finding relevant information, as well as advice on the best choices and solutions for end users, or even consciously react to their queries (Derks et al., 2008). IA surpasses basic RPA as it goes beyond a mere execution and repetition of particular process, in the same time focusing on how to improve and adjust its logic and flow, and strengthening it with probabilistic algorithms to achieve intelligent processing (Berrutti, et al., 2017). Nonetheless, as reported in most of the implementation cases, software robots are still intended to imitate human actions in various systems by tapping through a back-end or front-end integration mechanisms (Asatiani and Penttinen 2016).

Despite strong competitive and financial pressures that forces most of enterprises to consider implementing RPA, many organizations face serious challenges related to evaluation and selection of this technology. Between $30-50 \%$ of all RPA deployments fail because of misapplication (Ravn et al., 2016), as according to Gartner hype cycle for AI, inflated expectations lead to misunderstanding of full RPA potential and result in operational disruptions (Kenneth et al., 2019). The common initial challenge that many organisations face is suitability of RPA for the strategic goals and finding processes with automation potential (Vukšić et al., 2018). Further issues are often related to building automation pipeline and agile prioritization of cases, that allows for sustainable scaling of RPA across more and more business functions and teams (Bourgouin et. al, 2018). Another dilemma of many is the selection of an effective governance model, meaning which persons and units should be accountable for what (Kedziora and Penttinen, 2020). Infrastructural and technical challenges might also hinder the success of RPA implementation, related to server settings, access management, and operating system licensing, error handling, integration and scalability of RPA platform, installation and upgrading scenarios, as well as programming architecture (Syed et al., 2020).

Despite the growing interest in RPA among business organizations and academia, the scientific literature on the topic is still relatively scarce (Ivančić et al., 2019), though there has been conducted research on usage of other information technologies and automation modes deployed in healthcare sector. Poulymenopoulou et al. (2012) explored development of an information system for emergency care processes with use of mobile computing and cloud services, recommending further evaluation of other technologies in real environment of Emergency Medical Services (EMS) with frequent adverse circumstances, highlighting the effectiveness of centralized approach in providing integrated emergency care by both EMS agencies and hospitals. It allowed for better resources management and uniform triage of emergency cases regardless of the EMS agency contacted. Wan and Alagar (2015) have also indicated the need for further automating healthcare service in a patient-centric open distributed system, as it can provide dependable, 24/7 services for all people, in particular physically challenged, the elderly, and those who live in remote areas. Gaynor at al. (2014) put particular focus on the importance of balancing human expertise and automation in healthcare delivery, based on the deployment of IBM's Watson cognitive technology. Nonetheless, there has been found no papers on the implementation of RPA for emergency response (such as COVID-19 pandemic) in healthcare processes.

\section{Research Method}

The aim of the study is to uncover new insights on the phenomenon unexplored so far, thus it applies an exploratory approach. Hence, it focuses on discovery and enhancement the available of theory and practice, rather than testing (Sarker et al., 2019; Corbin and Strauss, 1990). Research questions have been responded to with an interview study with practitioners involved at RPA implementations for the City of Turku Welfare Division, in terms of different project roles. Moreover, analysed data got supplemented with additional materials, including reporting and controlling data, project documentation and communication memos. It is considered as an appropriate approach within an exploratory setting (Yin, 2009).

\subsection{Data collection}

The case lead originated from private network of the authors, and participants were invited to take part 
in the research in-person, as well as online via public and social media channels. The selection of interviewees was focused on reaching key stakeholders that took part in all implementations from various perspectives/with different roles, and some of them recommended other relevant persons to be contacted and asked for an interview. The discussions with interlocutors took place in May-June 2021 and each of them lasted about 30 minutes. Participation at semi-structured interviews was voluntary (not paid), so we needed to allow for the limited availability of responders. This type of work is characterized by having a flexible and fluid structure, yet the predefined topics and questions to cover are present (Mason, 2004). The following interlocutors based in Finland got interviewed:

\begin{tabular}{|l|l|l|}
\hline Informant & Organization & Role \\
\hline $\begin{array}{l}\text { 1. Program } \\
\text { Director }\end{array}$ & City of Turku & $\begin{array}{l}\text { Accountable for process } \\
\text { digitalization and } \\
\text { implementations of } \\
\text { information systems }\end{array}$ \\
\hline $\begin{array}{l}\text { 2. Deputy } \\
\text { Chief } \\
\text { Physician }\end{array}$ & $\begin{array}{l}\text { Turku Healthcare } \\
\text { Centre, Welfare } \\
\text { Division }\end{array}$ & $\begin{array}{l}\text { Accountable for } \\
\text { development of } \\
\text { administrative and } \\
\text { healthcare processes }\end{array}$ \\
\hline $\begin{array}{l}\text { 3. Public } \\
\text { Health Nurse }\end{array}$ & $\begin{array}{l}\text { Turku Healthcare } \\
\text { Division }\end{array}$ & $\begin{array}{l}\text { Expert in key } \\
\text { operational processes } \\
\text { that got automated }\end{array}$ \\
\hline $\begin{array}{l}\text { 4. IA Service } \\
\text { Manager }\end{array}$ & $\begin{array}{l}\text { NORIAN } \\
\text { Intelligent } \\
\text { Automation }\end{array}$ & $\begin{array}{l}\text { Management of } \\
\text { implementations }\end{array}$ \\
\hline $\begin{array}{l}\text { 5. IA Senior } \\
\text { Consultant }\end{array}$ & $\begin{array}{l}\text { NORIAN } \\
\text { Intelligent } \\
\text { Automation }\end{array}$ & $\begin{array}{l}\text { Technical design and } \\
\text { solution development }\end{array}$ \\
\hline
\end{tabular}

All the interviews were carried out in English and there were no communication barriers nor limitations during discussions. The lead researcher conducted and recorded interviews via video conferencing tool and took quasi-verbatim notes during the discussion time. Embedding the research into business practice was additionally strengthened by the professional experience of the first author who possesses over three years' work experience at one of the renowned intelligent automation consultancies. Hence, practitioners were interviewed on equal standing with the author from the perspective of natural authority. Because of that, it can be assumed that the note-taking practise did not affect validity, reliability, or transparency (Clausen, 2012); yet it saved time and eliminated misunderstandings.

The questions were to elicit the professional background and key responsibilities of interlocutors, followed by inquires related to the research questions. After the interviews, researchers made a reflection on how interlocutors perceived the questions and recognized emerging topics. The authors aimed to identify which topics triggered responses where interviewees recognized something potentially novel, such as specific decision factors, context of the studied implementations or difficulties, innovative ideas, solutions, or combination of processes and tools to solve some of these issues in the specific times of COVID-19 pandemic. Based on that, we requested some more explanations and secondary data, such as the implementation materials, process and project documentation, reporting and controlling data related to implemented solution.

\subsection{Data analysis}

The collected data got analysed with the inductive thematic and reflexive approach (Braun and Clarke, 2006). First, the authors inductively identified patterns in the experiences described by the interviewees, in terms of how the context of complex emergency triggered by the COVID-19 pandemic impacted the decision-making and implementation outcomes of RPA technology in the City of Turku. The analysis was reflexive, as the identified insights and themes additionally strengthened its objectivism by discussion and reflection on the collected data within the research team. It started by summarizing and describing experiences of interlocutors, built along the types of guiding questions (professional background and experience), later followed by discussions on the identified research questions. At the second stage of research work, the authors built upon the identified themes by further analysis on the reporting data received from Turku Healthcare Centre, as well as process and project documentation received from NORIAN Intelligent Automation. Moreover, communication memos and additional implementation materials got analysed and integrated at findings narrative to supplement and additionally extend the presented research.

\section{Findings and discussion}

This section shall be devoted to the presentation of case landscape and findings obtained from the informants and additional materials. Based on the interviews and observations on those case materials, multiple perspectives of RPA implementations as a solution for complex emergency response context can be assumed, bringing various types of value to different stakeholders. The results are discussed in 
terms of their connection and novelty to the previously reported deployments of RPA in academic literature.

\subsection{Setting}

In the spring of 2020, when COVID-19 pandemic hit Finland, the Welfare Division in the City of Turku Healthcare Centre experienced huge uncertainty, information instability, stress related to emergency, and inflow of virus contraction suspects. Initially, only persons with high fever and entering Finland from abroad were required to get tested. During the summer, new policy on performing tests and 'treatment need evaluation' for every person exposed to virus, or having even minor symptoms, created big workload increase at Turku Welfare Division. Additional 25 public nurses that got assigned to the former 100 nurses at Division experienced serious challenges in handling such difficult situation. In August, the number of phone calls presented in Figure 1 grew from the usual 2500 to over 60000 . The enormous time and emergency pressure made City of Turku decide to quickly search for a solution that was reliable, secure and fast to develop. The public tender process conducted with involvement of a company that acts as a partner of Turku City, aimed for deploying RPA to automate most of time-critical processes. NORIAN got selected as one of the top Nordic providers of Accounting, Payroll, and Intelligent Automation (IA) services. It allowed for quick setup of the project team, process analysis workshops and setup of IA architecture. As a result, five processes described below got automated and before the moving to discussions, the authors decided to explore all of them.

4.1.1. Turku Korona SMS. In this process, the robot searches for the laboratory test results of people, who have taken COVID-19 test in the province of Southwest Finland (City of Turku is the capital of the province). Then, it processes all of those, every 30 minutes. The robot performs acknowledgement of the results, on behalf of the healthcare professional, so that the results are published at "Omakanta" - web service maintained by The Social Insurance Institution of Finland. Every Finnish citizen can view there, for

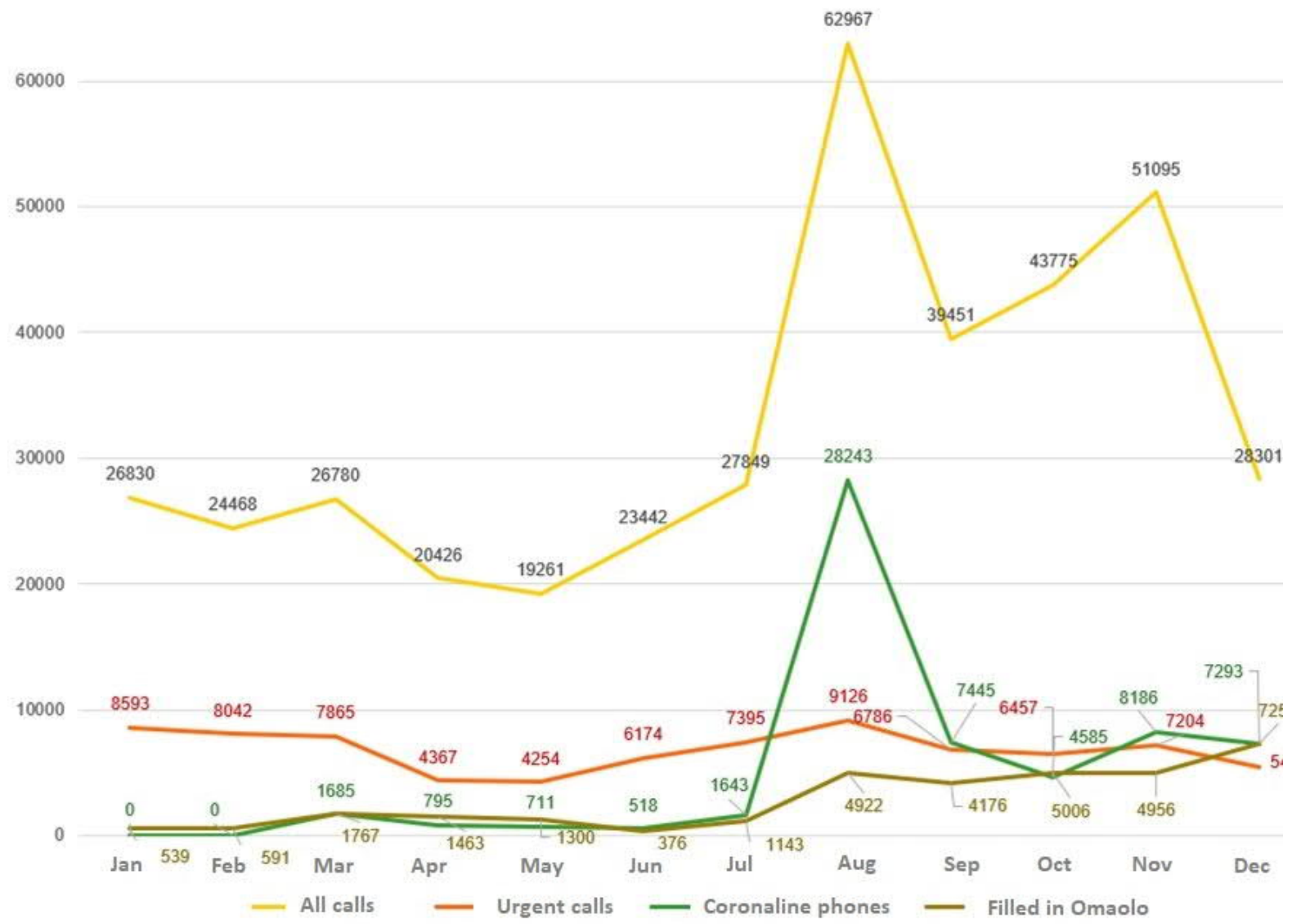

Figure 1. Calls received by Turku Healthcare Centre, Welfare Division in 2020 
example, their own medical records, medical subscriptions, and laboratory results. Hence, patients can check there that the robot has been processing their data, as it leaves them text describing the reason for processing the patient data. After that, the robot informs the person in question, or the guardian of the child, about the result using SMS sent from a number used by public authority to avoid the risk of fraud. In case of positive result, the robot is requesting an infected person to stay home. Then, healthcare professional contacts the person with further instructions. The people with negative result only get notification from the robot (SMS and Omakanta record). For automating this process, NORIAN implemented integration with one of the biggest teleoperators in Finland, so that the robot was able to send over 12000 SMS messages per month.

4.1.2. Turku Omaolo Referral. People in Finland were able perform a symptom assessment, on his/her own, at omaolo.fi website, which is created to guide people utilize correct healthcare services they need. On this website people can perform "omaolo oirearvio" ("how do you feel symptom assessment"). If symptoms are indicating a need for further examination - the website would guide the person to an examination laboratory close by, and let the person choose time. Because of COVID-19, several drivein/walk-in testing places got established in Finland, in addition to healthcare centers. The robot was fetching the people who were guided to COVID-19 testing in the province of Southwest Finland, and in a 30-minute time window the robot would create the laboratory appointment booking, laboratory examination referral - instructing and ordering the laboratory to take the CV19NhO test. Because the laboratory referrals were created on behalf of a doctor, each person guided to testing by the robot would see that the robot has been processing their medical records, by logging in to Omakanta-website (Finnish national healthcare registry). The robot would leave there a message: "In the Omaolo service, the patient completed the selfsymptom assessment of coronavirus disease and therefore booked an appointment for a laboratory examination. Let's make a laboratory referral.". A nurse was not able to take a test without a laboratory test assignment, so it was critical for the robot to operate continuously, to ensure people have the test ordered before they go to the testing place. After the laboratory referral, the robot was creating a patient report to the patient information system "Pegasos", so that the doctors will see what the case with the patient was earlier. If the patient was not found in the system, the robot would create a new patient profile in the patient information system, and in all cases, the robot would check that the person had an up-to-date phone number in the patient record. Another robot (Turku Korona SMS) would perform the acknowledgement and report the test result to the patient, when the laboratory results arrive, possibly already the next day.

4.1.3. Turku Corona Vaccination "Leila". This process focused on COVID-19 vaccinations. Robot receives a list of people selected by age groups, performs a time reservation, i.e. robot does an appointment with a nurse, for vaccination. The, the robot notifies the person via SMS where the vaccination takes place, which time, and which nurse. A hospital district chief physician controls the age groups and the amount of vaccination times, because vaccinations are not available in a predictable manner. The national authority, Finnish Institute for Health and Welfare, also keeps changing the recommendations, which vaccination can be given to which age group, so the process contains multiple exceptions and parts that get changed at usual basis.

\subsubsection{Turku Corona Vaccination Sign-Up} "Jenner". In COVID-19 "vaccination raffle" system (Koronarokotusarvonta), people willing to get vaccination had to register to the queue, and then they were randomly selected, based on the age criteria. The robot was performing time reservations for vaccination with a nurse. The robot would notify the person via SMS where the vaccination takes place, which time, and which nurse.

4.1.5. Turku Finentry. This robot was still under development in the time of the research. In this process, people arriving to Finland from abroad were required to get tested. The border authority would inform Turku of people arriving to the area by ship or airplane. People arriving would need to have a certificate of antigens for already suffered COVID-19 or a certificate of a negative lab result taken during the last 24 hours. If a traveller did not have a valid document, he/she was guided to testing, either via customs/harbour staff, or already by staff in the country of origin (person could fill details in Finentry portal before arriving to Finland). The robot would generate a temporary personal identity number for people from abroad, create a new local patient profile and generate a lab referral.

\subsection{Results}

For the personnel of the City of Turku, the deployment of the software robots was a completely new experience, they had no prior contact with RPA. According to Informants 1 and 4, the choice of RPA 
was not motivated by business case and cost savings but due to other key decision factors. RPA was chosen over the standard system integration, as it was faster to develop. The time it takes to prepare for an API change has already been discussed by Melville and Kohli (2021) who quoted: "You have to give us enough time because we have to change the application, we have to test the application, and deploy it.' Thus, it was not efficient to deploy any other technology than RPA when according to Informant 5 "the process should be implemented within 1 week when we are dealing with many systems, and normal integration would be taking several months". Another advantage of RPA in the emergency context is that it was relatively easy and fast to amend/change the logic of software robot, whenever requested. As later stated by Informant 5 "things and rules from government were changing very fast (...) and future was so uncertain on (...) should the robot work differently in one week? (...) and thanks to RPA we were able to be really agile and implement changes fast". Another aspect of substantial value for this context was that RPA allowed to automate larger parts of process than normal integration. As mentioned by Informant 4: "thanks to RPA we were able to automate almost endto-end process, imitating human work, including sending SMS, reading emails".

When it comes to the implementation project, RPA was warmly welcomed by operational workers. It is opposite to many research cases that reported some bias, or even panic among employees that got parts of their jobs automated. Informant 3 said "It was reliving as we have been quite under pressure here (...) yet we needed some time to understand how to work with the robot". Before automation, 20 physiotherapists and nurses had been occupied full time, creating the laboratory referrals, acknowledging results, and informing patients about the results, so the time saving among the stuff was substantial, yet as mentioned by Informant 2: "Our staff was so busy working with other problems induced by coronavirus that they didn't even notice to have more time (...) and sometimes patients call us only when really needed and they do not realize how much time we saved by these robots (...) automation was taken away from the growing amount of work, so some persons did not realized it helped so much", particularly in the era of huge nurses shortage on the labour market. As stated by Informant 4 , projects were fast and smooth, even though there were regulatory and compliance changes all the time from government and public actors. From project management perspective, there was no exceptional challenges in data protection, communication, nor financial aspects.
The issues with implemented robots were quite minor, as mentioned by Informant 2 "The phone numbers which can be wrongly put by patients might have been wrong and also nurses sometimes put them incorrectly, so that SMS goes to the wrong number". The challenge already found in previous literature was stated by Informant 1 " for some systems, there was no user ID for robots, only for human beings that required authentication with token ". Another reported issue was that Laura robot had issues with an integrated system. The issue was handled by texting system key users and asking to check what went wrong. Such approach to a processing issue has never been reported by any of available literature. Another issue was the quite big organization involved in the change, that required lots of time to conclude the best way of moving forward.

City of Turku received good feedback after deployment of software robots. The improved experience of patents was noticed, as the COVID-19 test results were delivered much faster than before. Informant 3 also mentioned that "robot working in 100 different languages is awesome, as it gives information to our patience who do not speak Finnish and such service could also be deployed for other processes and types of queries from patients". Software robots work also more hours than human workers. In this implementation, they were scheduled from 4 AM to 9 PM, seven days a week. Patients also get the information faster, about possible infection, as it earlier took from 2 to 10 days, until a healthcare professional contacts patient and informs about infection. Now, the result usually comes in 24 hours, which improved the quality of service dramatically.

An unusual finding of this research was the special feeling of mission and sense of serving society for all the involved stakeholders. Particularly for Informants 4 and 5 formerly helping commercial organization to optimize their business processes, this time it was more than a job, as stated by Informant 5 "the aim was to save lives, not just secure the payroll, and the people to stay healthier, by having less manual work to be wasted by nurses and doctors who can now concentrate on more important things and treating people in need".

As stated by all the stakeholders, it is desired and planned to extend automations in the future, to release more valuable workers from admin work that wastes their time, as it is very hard and expensive to recruit nurses in Finland. There are many ideas for further automations and scaling up RPA potential. Another element influencing this approach was mentioned by Informant 1 "there is number of kind of old school systems when there are no APIs, or development of such is so expensive and cumbersome, so it's better to 
use RPA“. For Turku Healthcare Centre, Welfare Division, the business case was not the key decision factor, but it was stated that the price for RPA services delivered was reasonable. Hence, RPA is planned to become the part of the City of Turku software stack, supporting not only Healthcare Centre, Welfare Division, but also other administrative units of the organization.

\section{Conclusions}

This case study observed the use of RPA in response to COVID-19 emergency in City of Turku Healthcare Division. Findings highlight the strong time pressure and need for deploying reliable solutions fast to ensure that nurses are released from administrative burden and can focus on helping patients with clinical assignments. RPA had been chosen over other middleware and integratory solutions mainly due to its fast implementation time and ability to get big parts or even entire processes automated. As for the contribution to the available literature, the explored case demonstrated that RPA can serve as the solution for COVID-19 emergency response, yet its implementation in this exceptional situation, at non-commercial sector was associated with different drivers and value added, compared to formerly reported commercial cases. In this situation, cost reduction was not the key decision factor. Moreover, none of the persons who got their process automated felt any bias/panic towards the change. All the stakeholders felt special due to the societal impact of the value brought by RPA. Fast implementation of RPA offered practical implications for healthcare and public decision makers to consider and release valuable time of healthcare and other public servants that are in shortage, at the same time maximizing their availability to serve us all, potential patients and customers of public administration. Such case differs from the commercial applications of RPA technology, as the types of value brought by automations are different than in previously reported research. The study limitations are related to capacity and availability of responders, as well as only one, single case that got addressed. Hence, it is recommended to further explore the types and elements of value brought by RPA technology in non-commercial contexts, such as complex emergencies and public healthcare organizations. Moreover, the authors encourage to compare its results against implementations of RPA technology at noncommercial contexts in developing countries, as some goals that might be impossible to achieve due to large population or financial conditions. It is also recommended in the future to explore the setting again and get more insights from patients and users of the implemented IA infrastructure.

\section{References}

Clausen, A. S. "The individually focused interview: Methodological quality without transcription of audio recordings.," Qualitative Report, vol. 17, pp. 37, 2012.

Aguirre, S. and Rodriguez, A. "Automation of a Business Process Using Robotic Process Automation (RPA): A Case Study. " in Conference: Workshop on Engineering Applications, p. 65-71. 2017.

Anagnoste, S. "Setting up a robotic process automation center of excellence." Management Dynamics in the Knowledge Economy, vol. 6, no. 2, pp. 307-332. 2018.

Asatiani, A. and Penttinen. E. "Turning robotic process automation into commercial success - Case OpusCapita." Journal of Information Technology Teaching Cases, vol. 6, np. 2, pp- 67-74. 2016.

Berrutti, F. Nixon, G. Taglioni, G. and Whiteman, R. "Intelligent process automation: The engine at the core of the next-generation operating model. " 2017. [cited 02.08.2021]. Available from: https://www.mckinsey.com/business-functions/digitalmckinsey/our-insights/intelligent-process-automationthe-engine-at-the-core-of-the-next-generationoperating-model

Bourgouin, A., Leshob, A. and Renard, L. "Towards a Process Analysis Approach to Adopt Robotic Process Automation". in ICEBE 2018 - 15th International Conference on e-Business Engineering, pp. 46-53. 2018.

Connolly, M. A., Gayer, M., Ryan, M. J., Salama, P., Spiegel, P., and Heymann, D. L. "Communicable diseases in complex emergencies: impact and challenges. “ The Lancet, vol. 364, no. 9449, pp. 19741983. 2004.

Derks, D., Fischer, A. and Bos, A. "The role of emotion in computer-mediated communication: A review. " Computers in Human Behavior. vol. 24, no. 3, pp. 766785. 2008.

Dumas, M., Rosa, ML., Mendling, J. and Reijers, HA. Fundamentals of business process management. Springer, 2018.

Fine, G. A. "Viral Buzz: Rumor and Its Disruptions in Pandemic Uncertainty. “ Sociologica (Bologna), vol. 15 , no. 1 , pp. 43-53. 2021

Gaynor, M., Wyner, G. and Gupta, A. "Dr. Watson? Balancing automation and human expertise in healthcare delivery." Lecture Notes in Computer Science, vol. 8803, pp. 561-569. 2014.

Geyer-Klingeberg, J., Nakladal, J., Baldauf, F. and Veit, F. "Process mining and robotic process automation: a perfect match." in Proceedings of the 16th international conference on business process management (BPM). vol. 2196, pp. 124-131. 2018.

Hallikainen, P., Bekkhus, R. and Pan, S.L. "How OpusCapita Used Internal RPA Capabilities to Offer Services to Clients." MIS Quarterly Executive. vol. 17, no. 1., pp. 41-52. 2018. 
Herm, L., Janiesch, C., Steinbach, T. and Wüllner, D. "Managing RPA implementation projects." in: Robotic Process Automation. (Czarnecki, C. and Fettke, P. eds.), pp. 27-46. De Gruyter Oldenbourg. 2021

Imgrund, F., Fischer, M., Janiesch, C. and Winkelmann, A. "Conceptualizing a framework to manage the short head and long tail of business processes." in 16th international conference business process management (BPM), Sydney. Lecture Notes in Computer Science, vol. 11080, pp. 392-408. 2018.

J. M. Corbin and A. Strauss, "Grounded theory research: Procedures, canons, and evaluative criteria," Qualitative Sociology, vol. 13, no. 1, p. 3-21, 1990.

Kedziora, D. and Kiviranta H.M. "Digital sales value cocreation with robotic process automation (RPA) of the finance and accounting industry in Northern and Central Europe.“ Management, vol. 13, no. 2, pp. 161174. 2018

Kedziora, D., and Penttinen, E. "Governance models for robotic process automation: The case of Nordea Bank." Journal of Information Technology Teaching Cases. vol. 11, no. 1, pp. 20-29. 2020.

Kedziora, D., Leivonen, A., Piotrowicz, W. and Öörni, A. "Robotic Process Automation (RPA) Implementation Drivers: Evidence of Selected Nordic Enterprises.“ Issues in Information Systems, vol. 22, no. 2, pp. 21-40. 2021.

Kenneth, B., Jim, H. and Svetlana, S. "Hype cycle for artificial intelligence." 2019. [cited 04.08.2021]. Available from https://www.gartner.com/ en/documents/3953603/hype-cycle-for-artificialintelligence-2019. accessed 11.6.2021

Lacity, M. and Willcocks, L.P. Robotic process automation at Telefónica O2., MISQ Executive. vol. 15, no. 2, pp. 21-35. 2016

Marius, I., Kristin, F., Marianne, K. and Salman, N. "The Level of Automation in Emergency Quick Disconnect Decision Making." Journal Of Marine Science And Engineering, vol. 6, no. 1. 2018

Mason, J.. "Semistructured Interview". in The SAGE Encyclopedia of Social Science Research Methods. (Michael, S., Lewis-Beck, A., Bryman, and Futing Liao, T., eds.), Sage publications. 2004.

Melville, N. and Kohli, R. "Roadblocks to Implementing Modern Digital Infrastructure: Exploratory Study of API Deployment in Large Organizations. " in Proceedings of the 54th Hawaii International Conference on System Sciences. pp. 5975-5984. 2021.

Mendling, J., Decker, G., Hull, Rr. Reijers, H and Weber, I. "How do Machine Learning, Robotic Process Automation, and Blockchains Affect the Human Factor in Business Process Management?" Communications of the Association for Information Systems. vol. 43. pp. 297-320. 2018.

Mija-Tesse, V., Phuoc, L., B, S. P. and Peter, S. "Occurrence and overlap of natural disasters, complex emergencies and epidemics during the past decade (1995-2004).“ Conflict and health, vol. 1, no. 1, pp. 1-9. 2007

Nakayama, I. "The New Work Style Innovation Enabled by AI and RPA.“ 2017 [cited 03.08.2021]. Available from: http://journal.jp.fujitsu.com/en/2017/12/27/01/
Osmundsen, K., Iden, J. and Bygstad, B. Organizing Robotic Process Automation: Balancing Loose and Tight Coupling. in Proceedings of the 52nd Hawaii International Conference on System Sciences, pp. 146155. 2019.

R. K. Yin, "Case study research: Design and methods." Sage publications, 2009.

Ravn, R., Halberg, P., Gustafsson, J. and Groes, J. "Get ready for robots: why planning makes the difference between success and disappointment." 2016 [cited 01.08.2021]. Available from: http://eyfinancialservicesthoughtgallery. ie/wpcontent/uploads/2016/11/ey-get-ready-for-robots.pdf.

Reuters "Robotic Process Automation (RPA) Market 2018 Key Highlights, Future Opportunities, Industry Trends, Share, Development Policies and Future Growth." 2018 [cited 01.08.2021]. Available from: https://marketersmedia.com/robotic-processautomation-rpa-market-2018-key-highlights-futureopportunities-industry-trends-share-developmentpolicies-and-future-growth-2023/405191

S. Sarker, S. Chatterjee, X. Xiao, and A. Elbanna. "The sociotechnical axis of cohesion for the is discipline: Its historical legacy and its continued relevance," MIS Quarterly, vol. 43, pp. 695-719. 2019.

Sampson, S. "Predicting Automation of Professional Jobs in Healthcare. "In 53rd Hawaii International Conference on System Sciences, HICSS 2020, 2020. pp. 1-9, 2020.

Santos, F., Pereira, R. and Braga Vasconcelos, J. "Toward robotic process automation implementation: an end-toend perspective“. Business Process Management Journal, vol. 26, no. 2, pp. 405-420. 2020.

Schmitz, M., Dietze, C. and Czarnecki, C. "Enabling digital transformation through robotic process automation at Deutsche Telekom.“ In: Digitalization cases. Springer, pp. 15-33. 2019.

Staaby, A. \& Hansen, K. \& Grønli, T-M. "Automation of Routine Work: A Case Study of Employees' Experiences of Work Meaningfulness." in Proceedings of the 54th Hawaii International Conference on System Science, pp. 156-165. 2021

Syed, R., Suriadi, S., Adams, M., Bandara, W., Leemans, S.J., Ouyang, C., ter Hofstede, A.H., van de Weerd, I., Wynn, M.T. and Reijers, H.A. "Robotic process automation: contemporary themes and challenges." Computers in Industry, vol. 115, pp. 1-15. 2020.

UiPath. "Citizen Developer Foundation" 2021 [cited 02.08.2021]. Available from: https://www.uipath.com/community/rpa-communityblog/citizen-developer-foundation-uipath-academycourse

van der Aalst, W.M.P., Bichler, M. and Heinzl, A. "Robotic Process Automation." Springer. 2018

Vukšić, B., V., Brkić, Lj., Tomičić-Pupek, K. "Understanding the success factors in adopting Business Process Management Software: case studies. “ Interdisciplinary description of complex systems. vol. 16, no. 2, pp. 194-215. 2018.

Wan, K. and Alagar, V. "Dependable healthcare service automation: A holistic approach. " Lecture Notes in Computer Science, vol. 9227, pp. 766-777. 2015. 
Wanner, J., Hofmann, A., Fischer, M., Imgrund, F., Janiesch, C. and Geyer-Klingeberg, J. "Process selection in RPA projects: towards a quantifiable method of decision making. " in Proceedings of the $40^{\text {th }}$ international conference on information systems (ICIS), pp. 1-17. 2019

Willcocks, L.P., Lacity, M. and Craig, A. "The IT function and robotic process automation. "The Outsourcing Unit Working Research Paper Series, vol. 15, no. 5. (2015) 